\title{
Are Demographic Diversity Effects Spurious?
}

\author{
Stephan Nüesch \\ Institute of Strategy and Business Economics, \\ University of Zurich, \\ Plattenstrasse 14, \\ CH-8032 Zürich, Switzerland \\ (Email: stephan.nuesch@isu.uzh.ch)
}

\begin{abstract}
The substantial literature on the relationship between demographic diversity and team performance yields weak and/or inconsistent results. Using match-level data of all games played in the German soccer league Bundesliga over six seasons, this paper analyzes age, race and tenure diversity of the fielded team under different model specifications to test the robustness of demographic diversity effects. The empirical results reveal that the correlations between demographic diversity and the outcome of the game are confounded by mean values of the demographic attributes and contextual covariates.
\end{abstract}

\section{INTRODUCTION}

The subject of diversity management enjoys enormous popularity in practice as well as in the scientific management literature. The review article of Harrison and Klein (2007) revealed that the number of diversity studies has nearly doubled every five years, rising from 19 papers in 1988 to 134 in 2003. According to the survey of Jackson, Joshi and Erhard (2003), the large majority of these papers (89\%) address demographic diversity as they test the influence of surface-level categories, such as gender, race and age, on organizational or team effectiveness. The payoff from the large and expanding diversity literature, however, is disappointing, as the "cumulative findings about the consequences of within-unit differences have been weak, inconsistent, or both" (Harrison and Klein 2007, p. 1199). Jackson et al. (2003, p. 810) concluded that "these studies yielded few discernible patterns in the results. For most diversity dimensions, the findings across studies were mixed." Several reasons for the weak cumulative results of this literature have been proposed: missing consideration of mediating and moderating contextual factors (Jackson et al. 2003, Van Knippenberg and Schippers 2007), lack of mean and non-linear effects of the diversity attributes (Sorenson 2002, Franck and Nüesch 2009), a weak conceptualization of the construct of diversity (Harrison and Klein 2007), or contradicting predictions of the theory of social categorization and similarity attraction on one hand and the informational and decision theories on the other (Williams and O'Reilly 1998). Using a large match-level data set of professional German soccer teams (1836 observations), this paper examines the relationship between demographic diversity of the fielded team and the final outcome of the game under different model specifications in 
order to analyze the robustness of demographic diversity effects in teams. In particular, this analysis tests whether the correlation between demographic diversity and team effectiveness is spurious, since it is produced through the operation of a third intervening variable. ${ }^{1}$ The empirical results reveal that significant positive correlations between age and tenure diversity and team performance are confounded by central tendencies of the demographic attributes and contextual covariates like the team's relative payroll. Controlling for the mean effects and the context of the match, neither age, nor race, nor tenure diversity of the fielded team significantly impacts team effectiveness.

The remainder of this paper is structured as follows: In section two, I give a short review of the theoretical and empirical literature on demographic diversity in teams. In section three, the data and variables as well as the empirical estimation approach and the results are explained. The last section concludes the discussion.

\section{THEORETICAL FOUNDATIONS}

As the title already mentions, this paper concentrates on demographic diversity. Lawrence (1997, p. 5) classifies demographic attributes into three categories: "attributes that describe immutable characteristics such as age, gender, and ethnicity; attributes that describe individuals' relationship with organizations, such as organizational tenure and functional area; and attributes that identify individuals' positions within society, such as marital status." Others define demographic diversity as diversity of all readily detectable attributes or surface-level diversity in contrast to underlying attributes or deep-level diversity such as diversity of personal attitudes, beliefs, values or abilities (Horwitz and Horwitz 2007). Since aspects like gender or functional diversity are irrelevant in the specific context of professional soccer, this paper defines demographic diversity as diversity of age, race and tenure. Differences regarding the marital status of the players are not tested due to data unavailability.

The theoretical literature on diversity in organizations can be divided into a positive and a negative perspective (William and O'Reilly 1998). The positive perspective mainly draws on theories of information and decision making that highlight the benefits of differential information resources. Different ethnic backgrounds, for example, may provide different distributions of skills and knowledge (Lazear 1999). The negative perspective draws on the theories of social categorization (Taifel 1981, Turner 1985) or similarity attraction (Byrne 1971). These theories suggest that diversity nurtures conflict and turnover and decreases social identification, cohesion, and performance. Given the contrasting theories, the overall effect of increasing demographic diversity is unclear (William and O'Reilly 1998).

The empirical literature that addresses demographic diversity effects in sports teams presents inconsistent results as well. ${ }^{2}$ Testing racial and age diversity of professional basketball and baseball teams, Timmerman (2000) found evidence that both diversity dimensions decreased

1 In this paper, we use the phrase "spurious correlation" or "spurious effect" to describe a situation in which two variables are related through their correlation with a third intervening variable (Wooldridge 2003). The term "spurious regressions" was established by the seminal paper of Granger and Newbold (1974), which explains how nonsense regressions can arise in time series data.

2 For references of demographic diversity studies in other sectors, consult the excellent review articles of Williams and O'Reilly (1998), Jackson et al. (2003), and Van Knippenberg and Schippers (2007). 
the team's winning percentage in basketball and were irrelevant in baseball. He explained the contradicting results by different levels of interaction and interdependence that moderate the effect of demographic diversity. Even though team-interdependence in soccer is more similar to that in basketball than in baseball, Andresen and Altmann (2006) discovered a positive influence of age and race diversity on a team's sporting success in the German soccer league. However, they do not control for contextual factors such as a team's financial situation, making this finding less persuasive. Estimating a team fixed effects model, Brandes, Franck and Theiler (2009) again found no significant influence of race diversity in German soccer. Whereas all three empirical studies used seasonal data, the paper of Haas and Nüesch (2009) was the first to employ match-level data, which results in a much larger number of observations. ${ }^{3}$ Haas and Nüesch (2009) discovered that multinational soccer teams perform worse than teams with less ethnic diversity, holding unobserved seasonal team heterogeneity constant. Unlike the abovementioned studies, this paper concentrates on the robustness of the diversity effects by estimating different model specifications.

\section{EMPIRICAL FRAMEWORK}

The sports business is an ideal laboratory to test various labor market theories (Kahn 2000). Due to the frequency and regularity of athletic events, large panel data sets are available that allow one to control for the (time-constant) team-specific context. In professional sports, team performance is clearly defined by the rules of the game and identified by independent referees, whereas most diversity studies rely on indirect performance measures or subjective ratings by team members and supervisors (Timmerman 2000). All teams face the same rules and restrictions, so hypotheses may be tested in relatively controlled field environments.

\subsection{Data Set and Dependent Variable}

This paper tests the relationship between age, tenure and race diversity and team performance using data of all games of the German soccer league Bundesliga over six seasons (2001/02 until 2006/07). With 18 teams playing each other twice during the season, a season includes 306 games, generating 612 team performance observations. Since the data set covers six seasons, it results in 3672 team performances from 1836 games. In order to account for the non-independence of observations within the same fixture, only one observation per match is used. Thus, a home or an away team was randomly selected under the condition that all teams are equally considered at home and on the road in order to prevent any selection bias.

The dependent variable is team performance as measured by the final score; this is a useful measure since it reflects the team's primary purpose of winning a soccer game by scoring more goals than the opposition. The measure goal difference allows using Ordinary Least Squares (OLS) estimates that are easier to interpret than an ordered probit or logit approach (win, draw, loss). In addition, unlike ordered probit or logit estimates, the unbiasedness and consistency of OLS estimators do not crucially rely on the normality and homoskedasticity of

3 Whereas both soccer papers (Andresen and Altmann 2006, Brandes et al. 2009) have a sample size of 90, the paper of Haas and Nüesch (2009) uses 4284 observations to test demographic diversity effects. The study of Timmerman (2000) incorporates 871 (basketball) and 1082 (baseball) observations. 
the error term (Wooldridge 2003). The model used here is similar to that of Carmichael et al. (2000) and Franck and Nüesch (2008), whose team production models were estimated using least squares techniques as well. ${ }^{4}$

\subsection{Demographic Diversity Variables}

Based on the playing strategy, the team's coach selects the players from the entire squad who will compete in a particular match. ${ }^{5}$ Injuries, sickness, or suspensions of players have to be considered as well, which implies that the demographic variables have sufficient variation even within the same club. In order to calculate match-specific diversity measures, I built a large data set containing all individual match appearances in the German Bundesliga over six seasons (in total 25,187 observations) as well as each player's age, tenure (in years) and race. The data were collected from special editions of the most prominent soccer magazine in Germany, Kicker, and the webpages www.kicker.de and www.fussballdaten.de.

Harrison and Klein (2007) specified diversity - which they defined as "the distribution of differences among the members of a unit with respect to a common attribute" (p. 1200) - as three distinct concepts: separation, variety, and disparity. Whereas separation and disparity measure horizontal and vertical differences, respectively, variety captures within-unit diversity of categorical data. Following the classification of Harrison and Klein (2007), age and tenure diversity are defined as separation, which is measured by the standard deviation. Thus, maximum age and tenure separation occurs when members are equally split at the opposing endpoints of the continuum. The use of disparity as a diversity concept would imply that tenure and age were socially valued and desired attributes such that having more is generally better than having less, like income, prestige or authority (Harrison and Klein 2007). Whereas in other contexts, tenure and/or seniority may clearly be associated with status and authority within the team, in professional soccer intra-group status depends more on individual field performances than on demographic attributes. Alternatively, tenure and age diversity might be conceptualized as variety as well. In this view, a team would include different cohorts of members having the same tenure or the same age, without, however, taking the inter-cohort distances into account. Normally, variety is only used for categorical attributes, such as functional background or ethnicity. Hence, race differences are defined as race variety that is measured by the Blau's index, defined by the formula $1-\sum p_{k}^{2}$, where $p_{k}$ is the proportion of players of a given nationality $k$. Maximum possible variety increases with the number of categories, but it cannot exceed one (Harrison and Klein 2007). ${ }^{6}$

\subsection{Mean Effects}

Mean values of the demographic attributes age and tenure act as the first group of potential confounding variables. Bedeian and Mossholder (2000) and Sorenson (2002) have argued that

4 In order to test the robustness of the results, I also estimated a $\mathrm{n}$ ordered probit estimation with the final result (win, draw, loss) as the dependent variable. The results, however, react insensitively to the alternative estimation procedure.

5 Since the teams in our sample have an average roster size of 26.1 players, only about half of the team members are allowed to play in a game.

6 All three match-specific diversity measures include the attributes of substitute players as well. Differences in playing time are not taken into account as this would largely distort the diversity measures. 
the risk of spurious results is high if the mean effects are not held constant. In particular, they criticized the "misuse" of the coefficient of variation as a single demographic measure as it incorporates two characteristics (the standard deviation and the inverted mean) that may have independent effects on team performance. Sorenson (2002) showed that the robust negative correlation between the turnover rate and tenure disparity, measured with the coefficient of variation, is not driven by tenure variability, but rather by the simple fact that those with higher tenure, and therefore with higher investments in firm-specific human capital, are less likely to leave. Since mean tenure decreases the turnover rate, the coefficient of variation appears to increase turnover even in the absence of any impact of tenure heterogeneity. As in real data, most attributes are restricted and have upper and lower bounds, the mean tends to be correlated with other variance measures like the standard deviation as well, which is why Harrison and Klein (2007) urge scholars to use the mean whenever testing diversity as disparity and separation. In the past, scholars have often been ignorant to the importance of mean effects. Reviewing 63 empirical papers on the effects of workplace diversity, Jackson et al. (2003) found that only $35 \%$ of them controlled for the central tendency when testing diversity effects. As will be seen in the subsequent sections, the introduction of the mean age and tenure of the fielded players into the model can indeed significantly change the diversity effects.

\subsection{Contextual Variables}

Jackson et al. (2003, p. 816) identified the lack of contextual information in past research as an explicit weakness of the diversity literature: "researchers usually provide very little information about the context in which a study was conducted". Organizational research can be contextualized by either directly incorporating contextual variables as covariates that may impact the results, or by doing comparative studies across institutions, sectors, activities or countries (Rousseau and Fried 2001). As this study concentrates on one activity - soccer - in one country - Germany - only the first strategy to conceptualize the study can be pursued. In the following, I explain the contextual covariates used in this paper.

In order to account for the possibility that location may influence a game's result and the demographic composition of the fielded team, a dichotomous variable home game is incorporated. Carmichael, Thomas and Ward (2000) discovered that the home team in the English Premier League scored 1.2 goals more on average than the away team, controlling for the unobserved playing strength of the team and numerous field performance measures. In addition, we have to control for the team's playing strength in relation to the opposition team. This measure is likely to be associated with both the likelyhood of winning the game and the composition of the fielded team, as richer clubs are, for example, less restricted when engaging a foreign star player. Since there is a competitive market for the services of professional soccer players, the payroll of a team well reflects the playing strength and hence the team's performance (Syzmanski 2000). Thus, the model controls for the logarithm of the ratio of wage expenditures of the competing teams on field. Officially, German clubs do not have to publish player salaries. The Kicker soccer magazine, however, publishes salary estimates at the beginning of each new season. Since the estimates have been conducted in a systematic manner for several years by a mostly static editorial staff, they are likely to be consistent and have, therefore, been used in several empirical studies so far (for an excellent review, see Torgler and Schmidt 2007). The 
variable log relative wage expenditures is calculated using the same data source.

Since the coach chooses the players for a particular match, coach-specific preferences and attitudes are likely to affect both the composition of the fielded team and the team's effectiveness. Since a coach's playing strategy and partialities are typically unobserved, I use individual fixed effects to account for the time-constant aspects that may influence a coach's player selection. Besides these match-specific controls, fixed effects of both teams on the field are included to account for unobserved team heterogeneity that may bias the relationship between demographic diversity and team performance. Seasonal dummies are used to control for time-effects. Table 1 illustrates the variables as well as the descriptive statistics.

Table 1: Variables and Descriptive Statistics

\begin{tabular}{|c|c|c|c|c|c|}
\hline Variable & Description & Mean & $\mathrm{SD}$ & Min & Max \\
\hline \multicolumn{6}{|l|}{ Diversity constructs } \\
\hline Age separation & Standard deviation in age of the fielded players & 3.99 & 0.68 & 1.86 & 6.11 \\
\hline Race variety & $\begin{array}{l}\text { Blau index of the nationalities of the fielded } \\
\text { players }\end{array}$ & 0.72 & 0.12 & 0.13 & 0.91 \\
\hline Tenure separation & $\begin{array}{l}\text { Standard deviation in tenure of the fielded } \\
\text { players }\end{array}$ & 2.15 & 0.78 & 0.65 & 5.29 \\
\hline \multicolumn{6}{|l|}{ Mean effects } \\
\hline Mean age & Average age of the fielded players & 26.71 & 1.14 & 22.62 & 30.64 \\
\hline Mean tenure & Average tenure of the fielded players & 2.11 & 0.78 & 0.90 & 5.36 \\
\hline \multicolumn{6}{|l|}{ Contextual variables } \\
\hline Home game & Games played in the home stadium (dummy) & 0.50 & & & \\
\hline $\begin{array}{l}\text { Log relative wage } \\
\text { expenditures }\end{array}$ & $\begin{array}{l}\text { Logarithm of the ratio of wage expenditures of } \\
\text { the competing teams (adjusted for inflation) }\end{array}$ & 0.00 & 0.57 & -1.70 & 1.70 \\
\hline
\end{tabular}

Notes: Model 4 also includes fixed effects for the coaches and for both teams on the field as well as a time trend.

\subsection{Results}

In order to detect potential spurious correlation, I test whether the relationship between demographic diversity and team performance persists or disappears when additional variables are introduced. ${ }^{7}$ Table 2 shows the estimation results of four separate models. The first specification only includes the diversity constructs and then mean effects are added, and in models 3 and 4, the contextual factors are included as well. Potential non-linearity between demographic diversity and team success is examined by the Ramsey's RESET test using powers of the individual regressors. The null-hypothesis of no misspecification is not rejected in all four specifications.

The estimation results of the first model in Table 2 show that age and tenure separation are positively related to the outcome of a match, whereas race variety does not affect the goal differential as dependent variable. After introducing the mean effects in model 2 , the effect of tenure separation disappears, however. The significant correlation between tenure separation and team success is spurious, as both variables are related through their correlation with a third

7 See also Simon (1954) regarding this procedure to detect spurious correlations. 
variable, mean tenure (see the Pearson correlation coefficients in Table 3). Tenure separation is positively associated with mean tenure (correlation of 0.77 ), which is positively correlated with goal difference (correlation of 0.11 ). The coefficient of the variable age separation is smaller in model 2 than in model 1, but it still remains statistically significant. Mean age neither significantly correlates with the dependent variable nor with age separation. The reduction of the coefficient is, rather, induced by the variable mean tenure, which displays a significantly positive correlation of 0.26 with age separation (see Table 3 ).

Table 2: Estimates of the Relationship between Demographic Diversity and Sporting Success

\begin{tabular}{|c|c|c|c|c|c|c|c|c|}
\hline \multirow{2}{*}{ Variables } & \multicolumn{2}{|c|}{1} & \multicolumn{2}{|c|}{2} & \multicolumn{2}{|c|}{3} & \multicolumn{2}{|c|}{4} \\
\hline & Coef. & Std. Err. & Coef. & Std. Err. & Coef. & Std. Err. & Coef. & Std. Err. \\
\hline \multicolumn{9}{|l|}{ Diversity constructs } \\
\hline Age separation & $0.166^{* *}$ & 0.064 & $0.141 * *$ & 0.064 & 0.079 & 0.060 & 0.061 & 0.082 \\
\hline Race variety & -0.106 & 0.363 & -0.077 & 0.362 & 0.116 & 0.331 & -0.004 & 0.343 \\
\hline Tenure separation & $0.126 * *$ & 0.053 & -0.116 & 0.084 & -0.049 & 0.079 & -0.083 & 0.115 \\
\hline \multicolumn{9}{|l|}{ Mean effects } \\
\hline Mean age & & & -0.020 & 0.037 & 0.022 & 0.034 & 0.015 & 0.058 \\
\hline Mean tenure & & & $0.322 * *$ & 0.084 & 0.009 & 0.083 & -0.053 & 0.132 \\
\hline \multicolumn{9}{|l|}{ Contextual variables } \\
\hline Home game & & & & & $0.885 * * *$ & 0.078 & $0.888 * * *$ & 0.077 \\
\hline $\begin{array}{l}\text { Log relative wage } \\
\text { expenditures }\end{array}$ & & & & & $0.989 * * *$ & 0.075 & $0.378 *$ & 0.221 \\
\hline Coach fixed effects & & & & & no & & yes*** & \\
\hline Team fixed effects & & & & & no & & yes*** & \\
\hline $\begin{array}{l}\text { Opposition team fixed } \\
\text { effects }\end{array}$ & & & & & no & & yes*** & \\
\hline Seasonal fixed effects & & & & & no & & yes** & \\
\hline $\mathrm{R}^{2}$ & \multicolumn{2}{|c|}{0.010} & \multicolumn{2}{|c|}{0.016} & \multicolumn{2}{|c|}{0.155} & \multicolumn{2}{|c|}{0.233} \\
\hline Observations & \multicolumn{2}{|c|}{1836} & \multicolumn{2}{|c|}{1836} & \multicolumn{2}{|c|}{1836} & \multicolumn{2}{|c|}{1836} \\
\hline
\end{tabular}

Notes: Ordinary Least Squares (OLS) estimation with White robut standard error. The dependent variable is the goal difference of a match. The RESET test for non-linearity is insignificant in all models. Significance levels (two-tailed): *10\%; **5\%; ***1\%.

Table 3: Pearson Correlation Coefficients

\begin{tabular}{|c|c|c|c|c|c|c|c|c|c|}
\hline & & 1 & 2 & 3 & 4 & 5 & 6 & 7 & 8 \\
\hline 1 & Goal difference & 1.000 & & & & & & & \\
\hline 2 & Age separation & $0.076^{* * *}$ & 1.000 & & & & & & \\
\hline 3 & Race variety & -0.010 & -0.027 & 1.000 & & & & & \\
\hline 4 & Tenure separation & $0.070 * *$ & $0.256 * * *$ & -0.014 & 1.000 & & & & \\
\hline 5 & Mean age & -0.002 & 0.012 & 0.031 & 0.011 & 1000 & & & \\
\hline 6 & Mean tenure & $0.113 * * *$ & $0.262 * * *$ & -0.024 & $0.772 * * *$ & $0.077 * * *$ & 1.000 & & \\
\hline 7 & Home game & $0.244 * * *$ & 0.017 & $-0.057 * *$ & 0.005 & -0.021 & 0.003 & 1000 & \\
\hline 8 & $\begin{array}{l}\text { Log relative wage } \\
\text { expenditures }\end{array}$ & $0.308 * * *$ & $0.153 * * *$ & -0.010 & $0.257 * * *$ & $-0.057 * *$ & $0.366 * * *$ & 0.000 & 1.000 \\
\hline
\end{tabular}

Notes: Significance levels (two-tailed): *10\%; **5\%; ***1\%. 
After incorporating a dummy indicating a home game and a measure of relative playing ability in model 3 , none of the demographic variables exert a statistically significant influence on the game's result. The Pearson correlation coefficients in Table 3 indicate that the significant correlations between age separation as well as mean tenure and the dependent variable in model 2 may be driven by their relation with the team's log relative wage expenditures as a third intervening variable. Fixed effects for both teams on the field and for the coach of the considered team as well as seasonal dummies explain additional $7.8 \%$ in the variation of the dependent variable in model 4 , but they do not alter the estimated demographic effects. Thus, no evidence of a causal connection between the age, race and tenure composition of the fielded team and team effectiveness is found.

The final outcome of a match is determined by contextual factors rather than demographic diversity. At home, a team scores approximately 0.9 goals more than on the road, holding everything else constant. In addition, the outcome of a game is strongly affected by the team's relative financial power, which allows attracting superior talent by offering comparably higher salaries. Finally, unobserved team and coach heterogeneity also impact the final score of a game.

\section{CONCLUDING REMARKS}

Are demographic diversity effects spurious? The empirical results of this paper suggest this to be the case. Using extensive match-level data of professional soccer teams, I have shown that significant correlations between age and tenure diversity and team performance are confounded by mean values of the demographic attributes and contextual aspects, such as the team's relative payroll. Holding these "third variables" constant, neither age, nor race, nor tenure diversity significantly affects the final outcome of a game. This does not necessarily mean that demographic diversity is irrelevant per se. Even though Keidel (1987) and Katz (2001) argue that professional sports teams provide an accurate representation of work teams in organizations, I cannot deny some important differences that may limit the generalization of the results. In project teams, for example, which spend comparably more time on strategy formulation and innovation (exploration) and less time on coordination and interaction (exploitation), demographic diversity might play another role than in performance teams. In addition, unlike typical work groups, professional sports teams are constantly and directly competing against other teams. Hence, a potential in-group/out-group distinction is more likely to occur between teams than within teams (Timmerman 2000), which diminishes the relevance of demographic homogeneity in order to facilitate social categorization and team cohesion. Nevertheless, the presented results emphasize the importance of accurately controlling for mean demographic effects within the team and the team's context when testing demographic diversity.

In this paper, we have considered spurious correlations as a situation in which two variables are related through their correlation with a third intervening variable. However, strictly speaking, this is only part of the story. Simon (1954, p. 468) has explained this issue in the following way:

"If we are suspicious that the observed correlation may derive from "spurious" causes, we introduce a third variable, $\mathrm{z}$, that we conjecture, may account for this observed correlation. We 
next compute the partial correlation, $\mathrm{r}_{\mathrm{xy}, \mathrm{z}}$ between $\mathrm{x}$ and $\mathrm{y}$ with $\mathrm{z}$ "held constant," and compare this with the zero order correlation, $r_{x y}$. If $r_{x y, z}$ is close to zero, while $r_{x y}$ is not, we conclude that either: (a) $\mathrm{z}$ is an intervening variable - the causal effect of $\mathrm{x}$ on $\mathrm{y}$ (or vice versa) operates though $\mathrm{z}$; or (b) the correlation between $\mathrm{x}$ and $\mathrm{y}$ results from the joint causal effect of $\mathrm{z}$ on both those variables, and hence this correlation is spurious. (...) in any event, the correlations do not tell us whether we have case (a) or (b)."

Aclear theoretical foundation of the natural causes and intervening processes is required in order to make the important distinction between "so-called spurious" relationships that are in fact genuine indirect correlations and "accidental spurious" correlations for which no sensible causal interpretation can be provided (Haig 2003). In the field of organizational demography, such an exact theory is missing, unfortunately. Lawrence (1997) speaks about the "black box of organizational demography" and argues that the additional theoretical concepts about the complex relationship between demographic diversity and group functioning are either inexistent or weakly supported by empirical evidence. The latter applies, for example, to the important congruence assumption in the demographic diversity literature, namely, the assumption that visible traits, such as age, gender and race, are reasonable substitutes for important underlying differences, such as beliefs, values, or abilities (Lawrence 1997). As long as the link between specific demographic variables, underlying psychological constructs and processes and team effectiveness is not explicitly theorized and empirically verified, scholars (including myself) are not able to discern between genuine indirect effects and accidental spurious correlations. Thus, amplified endeavors in theory development are necessary to explore the chain of causation between demographic diversity and team effectiveness in greater depth.

\section{ACKNOWLEDGEMENTS}

Fruitful discussions with Leif Brandes and Philipp Theiler inspired my work. I am grateful to Stephan Veen for helpful comments. Nicolai Grüter provided excellent research assistance.

\section{REFERENCES}

Andresen, M. and T. Altmann (2006). Diversity und Erfolg im Fussball (Diversity and Success in Soccer), Zeitschrift für Organisation. 75: 325-332.

Bedeian, A.G. and K.W. Mossholder (2000). On the Use of the Coefficient of Variation as a Measure of Diversity, Organizational Research Methods. 3: 285-297.

Brandes, L., E. Franck, and P. Theiler (2009). The Effect of National Diversity on Team Production - Empirical Evidence from the Sports Industry, Schmalenbach Business Review. 61, 225-246.

Byrne, D. (1971). The Attraction Paradigm. New York: Academic Press.

Carmichael, F., D. Thomas, and R. Ward (2000). Team Performance. The Case of English Premiership Football, Managerial and Decision Economics. 21: 31-45.

Franck, E. and S. Nüesch (2009). The Effect of Wage Dispersion on Team Outcome and the Way Team Outcome is Produced. Forthcoming Applied Economics.

Franck,E. and S. Nüesch (2008). The Effect of Talent Disparity on Team Productivity,Institute for Strategy and Business Economics University of Zurich, Working Paper No. 87, Zurich, Switzerland.

Granger,C.W.J. and P.Newbold (1974). Spurious Regressions in Econometrics, Journal of Econometrics. 2: 111-120.

Haas, H. and S. Nüesch (2009). Are Multinational Teams more Successful?. Unpublished Manuscript, University of Zurich, Switzerland. 
Haig, B.D. (2003). What is a Spurious Correlation?, Understanding Statistics. 2: 125-132.

Harrison,D.A. and K.J.Klein (2007). What's the Difference? Diversity Constructs as Separation, Variety, or Disparity in Organizations, Academy of Management Journal. 32: 1199-1228.

Horwitz, S.K. and I.B. Horwitz ( 2007). The Effect of Team Diversity on Team Outcomes: A MetaAnalytic Review of Team Demography, Journal of Management. 33: 987-1015.

Jackson, S.E.,A.Joshi, and N.L.Erhardt (2003). Recent Research on Team and Organizational Diversity: SWOT Analysis and Implications, Journal of Management. 29: 801-830.

Kahn,M.L.(2000). The Sports Business as a Labor Market Laboratory, Journal of Economic Perspectives . 14: $75-94$.

Katz, N. (2001). Sports Teams as a Model for Workplace Teams: Lessons and Liabilities, Academy of Management Executive. 15: 56-67.

Keidel, R.Q. (1987). Team Sports Models as a Generic Organizational Framework, Human Relations. 40: 591-612.

Lawrence, B.A. (1997). The Black Box of Organizational Demography, Organizational Science. 8: $1-22$.

Lazear, E.P. (1999). Globalization and the Market for Team-Mates, The Economic Journal. 109: 1540.

Rousseau, D.M. and Y. Fried (2001). Location, Location, Location: Contextualizing Organizational Research, Journal of Organizational Behavior. 22: 1-13.

Simon, H. (1954). Spurious Correlation: A Causal Interpretation, Journal of the American Statistical Association. 49: 467-479.

Sorenson, J. (2002). The Use and Misuse of the Coefficient of Variation in Organizational Demography Research, Sociological Methods and Research.30: 475-491.

Szymanki, S. (2000). A Market Test for Discrimination in the English Professional Soccer Leagues, Journal of Political Economy. 18: 590-603.

Tajfel, H. (1981). Human Groups and Social Categories: Studies in Social Psychology. Cambridge: Cambridge University Press.

Timmerman, T.A. (2000). Racial Diversity, Age Diversity, Interdependence, and Team Performance, Small Group Research. 31: 592-606.

Torgler, B. and S.L. Schmidt (2007). What Shapes Player Performance in Soccer? Empirical Findings from a Panel Analysis, Applied Economics. 39: 2355-2369.

Turner, J.C. (1985). Social Categorization and the Self-Concept: A Social Cognitive Theory of Group Behavior. Advances in Group Processes, Theory and Research. 2: 77-122.

Van Knippenberg, D. and M.C. Schippers (2007). Work Group Diversity, Annual Review of Psychology. 58: 515-541.

Williams, K.Y. and C.A. O'Reilly (1998). Demography and Diversity in Organizations: A Review of 40 Years of Research, Research in Organizational Behavior. 20: 77-140.

Wooldridge, J.M. (2003). Introductory Econometrics. A Modern Approach. Mason, OH: Thomson South-Western. 